\title{
Transthoracic Echocardiographic Hemodynamic Assessment in Patients under Spinal Anesthesia in Lower Limb Surgery
}

\author{
Sameh M Elsherbiny, Ahmed M Elaidy, Aboelnour M Badran, Ola T Abdeldayem
}

\begin{abstract}
Department of anesthesia, ICU and pain management, faculty of medicine, Mansoura University, Egypt.

Correspondence to: Sameh M Elsherbiny, department of anesthesia, ICU and pain management, faculty of medicine, Mansoura University, Egypt.
\end{abstract}

Email:

smfsherbiny@yahoo.com

Received: 28 June, 2020

Accepted: 2 August, 2020

\begin{abstract}
:
Background: Spinal anesthesia is often associated with significant hypotension due to a sympathetic block and can increase the risk of perioperative cardiac complications. Transthoracic echocardiography (TTE) is widely used throughout medicine as a clinical, diagnostic and research tool. Portability, accuracy, ease of use and a variety of training courses have encouraged its use. Aim: The present study was designed to evaluate the hemodynamic changes of spinal anesthesia by Transthoracic Echocardiography and test its efficacy as a monitoring tool in lower limb surgery. Methods: The study included 50 patients, who were scheduled for lower limb surgery under spinal anesthesia. Two serial TTE studies were performed. One immediately before spinal anesthesia after giving the preload, then at 10 mins after spinal anesthesia. Changes of heart rate
\end{abstract} (HR), mean arterial blood pressure (MAP), the total doses of ephedrine and atropine, and data regarding highest sensory level and bromage scale were recorded. Results: Echocardiographic monitoring the heart variables have showed marked decrease when MAP was $<70 \%$ of basal values. Conclusion: Transthoracic echocardiography has proved its efficacy as a monitoring tool in assessment and guiding the management of hemodynamic changes after spinal anesthesia.

Key words: Transthoracic echocardiography, Spinal anesthesia, Hypotension, Hemodynamic instability.

List of Abbreviations: American Society of Anesthesiologists (ASA), CI (Cardiac index), HR (heart rate), LVEDV (Left ventricular end diastolic volume), LVESV (Left ventricular end systolic volume), MAP(mean arterial blood pressure), PA(Pulmonary artery), RV(right ventricle), SV (Stroke volume), SVR (Systemic vascular resistance), TTE (Transthoracic echocardiography). 



\section{Introduction}

Spinal anesthesia is often associated with significant hypotension which can increase the risk of perioperative cardiac complications (1). Hypotension induced by spinal anesthesia is usually due to a sympathetic block leading to both a decrease in systemic vascular resistance (SVR) from arterial vasodilation, as well as a drop in cardiac output $(\mathrm{CO})$ due to a decrease in preload from venodilation with blood redistribution to the lower limbs (2).

During spinal anesthesia, sympathetic blockade is the first event to occur, and the last to disappear. This blockade causes hemodynamic instability, such as hypotension and delayed bradycardia, which is critical to recognize and prevent early, in order to avoid dramatic consequences such as cardiac arrest (3). Coupling perioperative functional hemodynamic monitoring with protocols to optimize oxygen delivery reduces complications, postoperative length of stay and overall mortality (4).

No single monitoring device provides a complete evaluation of hemodynamic status; as well as many devices are available with their own benefits and limitations (5). Simple non-invasive devices measure blood pressure, heart rate and cardiac output, but may be inaccurate in the setting of marked peripheral vasoconstriction. Minimally invasive (arterial catheterization) and more invasive (central venous and pulmonary artery catheterization) devices directly measure cardiac output, but may be time consuming to place and are more prone to complications.

Between these extremes, there are array of devices that indirectly determine cardiac output and assess preload responsiveness (6). Echocardiography has become the most informational point-of-care cardiac imaging modality for one's ability to analyze the structure and function of the heart, while providing medical/surgical interventions simultaneously, to help improve a patient's cardiac function (7).

The use of echocardiography leads to a change in diagnosis and change in hemodynamic management in $40-60 \%$ of cases (8). The American Society of Anesthesiologists (ASA) members agreed to the use of echocardiography in patients undergoing non-cardiac surgery and showing persistent hypotension in spite of intervention (9). 
Transthoracic echocardiography (TTE) is widely used throughout medicine as a clinical, diagnostic and research tool (10). The TTE is non-invasive and has no known adverse effects. Unlike a formal cardiology based TTE which can often take 45 to 60 minutes, a focused goal- directed study to answer a particular question is often more appropriate in the perioperative period and can be performed in as little as 10 minutes (11). Portability, accuracy, ease of use and a variety of training courses have encouraged its use (12). The rationale of this study is to assess if the use of TTE may be advantageous to conventional cardiovascular monitoring in management of perioperative hemodynamic instability during spinal anesthesia. The present study was designed to evaluate the hemodynamic changes of spinal anesthesia by Transthoracic Echocardiography and test its efficacy as a monitoring tool in lower limb surgery.

\section{Patients and Methods:}

This prospective observational study included 50 ASA I and II patients, aged between 20 and 40 years old of both genders, who were scheduled for lower limb surgery under spinal anesthesia. It was conducted for one year (from January 2017 to January 2018) in Emergency Hospital in
Mansoura University after getting approval from Institutional Research Board (IRB), Mansoura Faculty of Medicine. Informed written consent was obtained from all patients in the study after ensuring confidentiality. Exclusion criteria were contraindication for spinal anesthesia (patient refusal, coagulopathy, infection), uncorrected hypovolemia, anemia with a hemoglobin $<10 \mathrm{~g} / \mathrm{dL}$, congestive heart failure, myocardial ischemia, atrial fibrillation, valvular heart disease, pregnancy and morbid obesity (BMI $\geq 40$ $\left.\mathrm{kg} / \mathrm{m}^{2}\right)$.

Patient demographic data including age, sex, body surface area (BSA), body mass index (BMI) were recorded. All patients were subjected to preoperative assessment including: history taking, clinical examination, laboratory investigations (complete blood count, coagulation profile, blood sugar, liver and renal function tests), in addition to electrocardiograph (ECG). Details of the anesthetic technique and the study protocol were explained to all patients involved in the study.

Patients were kept fasting prior to surgery according to pre-operative ASA recommendations. An 18-gauge intravenous cannula was established, Basic monitors were applied (ECG, pulse 
oximetry, noninvasive $\mathrm{BP}$ ), and baseline values were recorded. No medication or anesthetic drugs were given before the preoperative TTE measurements. All patients received $10 \mathrm{ml} / \mathrm{kg}$ Ringer lactate as a preload over 20 minutes. Spinal anesthesia was given using a 25-gauge needle while the patient was in the sitting position, then patients received hyperbaric bupivacaine (15 $\mathrm{mg})+$ fentanyl $(25 \mu \mathrm{g})$. Sensory block was assessed by the loss of cold sensation using an alcohol-soaked gauze pad bilaterally, while motor block was tested by modified bromage scale (0: no motor block, 1 : straight leg hip flexion blocked, 2: knee flexion blocked, 3: complete motor block). If hypotension (MAP $<20 \%$ of baseline value, or MAP < $60 \mathrm{mmHg}$ ) occurred, it was treated with i.v increments of $5 \mathrm{mg}$ ephedrine as needed. If bradycardia (HR is < 50 beats/min) occurred, i.v atropine (0.01 $\mathrm{mg} / \mathrm{kg}$ ) was given.

Two serial TTE studies were performed under standardized conditions, one immediately before spinal anesthesia after giving the preload, then at 10 mins after spinal anesthesia. A parasternal long axis (PLAX), parasternal short axis (PSAX), subcostal, apical four and five chamber (A4C, A5C) TTE examination including two-dimensional imaging and pulsed wave
Doppler were performed. The left ventricular outflow tract (LVOT) image was obtained from the PLAX view. The zoomed LVOT image was frozen during systole. End systole was defined as the image preceding early diastolic mitral valve opening, while end diastole was at the onset of the $\mathrm{Q}$ wave of the QRS complex. LVOT diameter was measured perpendicular to the aortic root, three readings were measured and the average of them was recorded. The LVOT velocity time integral (VTI) was obtained using the A5C view. A good quality image was assessed by maximal chamber size, a vertical long axis and maximal mitral valve opening size. Pulsed wave Doppler was placed within the LVOT about $0.5 \mathrm{~cm}$ proximal to the aortic valve. VTI was measured by tracing the leading edge of the velocity spectrum of three consecutive beats and their average measurement was recorded.

Heart rate $(\mathrm{HR})$ and Mean arterial blood pressure (MAP) were recorded before spinal anesthesia, then every minute for ten minutes, then every two minutes for another ten minutes post spinal. The total doses of ephedrine and atropine and data regarding highest sensory level and bromage scale were recorded. Images from the TTE were used to obtain the following data: 
(1) Data from the left side of the heart:

- Left atrial diameter, LVEDD, LVESD, LVEDV, LVESV.

- $\mathrm{SV}=\mathrm{VTI} \times$ cross sectional area of the LVOT (cross sectional area of the $\left.\mathrm{LVOT}=\mathrm{LVOT}_{\text {diameter }}{ }^{2} \mathrm{x} 0.785\right)$.

- Cardiac output: $\mathrm{CO}=\mathrm{HR}$ x SV.

- Cardiac index: $\mathrm{CI}=\mathrm{CO} / \mathrm{BSA}$.

- Ejection fraction: EF= EDV-ESV/EDV and fractional shortening (FS).

- Systemic vascular resistance: $\mathrm{SVR}=$ MAP / CO.

(2) Data from the right side of the heart:

- Right atrial and ventricular diameters.

- RV diastolic \& systolic areas and volumes.

- PA diameter\& PA systolic pressure.

- IVC diameter: from the subcostal view.

\section{Statistical analysis:}

The collected data were coded, processed, and analyzed using SPSS program (version 22) for Windows. Normality of numerical data distribution was tested by KolmogorovSmirnov test. Normally distributed numerical data were presented as mean and standard deviation, and compared in different groups using one-way ANOVA with post-hoc Bonferroni test, while in the same group using repeated measures ANOVA with post-hoc Dunnett's test. Non- normally distributed numerical data were presented as median and range, and compared non-parametrically using KruskalWallis test followed by Mann-Whitney U test. As well, categorical data were presented as number, and compared using Chi-square test. All data were considered statistically significant if $\mathrm{P}$ value is $\leq 0.05$.

\section{Results:}

After collecting data of patients, patients were allocated in three groups according to changes in MAP: A, B and C. Group A: patients with blood pressure $>80 \%$ of basal values $(\mathrm{N}=29)$. Group $\mathrm{B}$ : patients with blood pressure $\leq 80 \% \& \geq 70 \%$ of basal values $(\mathrm{N}=16)$. Group $\mathrm{C}$ : patients with blood pressure $<70 \%$ of basal values $(\mathrm{N}=5)$. Patients in the three groups were comparable and showed no statistically significant difference as regard demographic data $(\mathrm{P}<$ 0.05) Table (1).

With respect to assessment of spinal anesthesia, there was a statistically significant difference between group (C) in comparison to group (A) and (B) as regard the highest sensory level $(\mathrm{P}=0.04)$ Table (2). However, there was no statistically significant difference between the three groups as regard motor block (Bromage score $)(\mathrm{P}<0.05)$ Table $(2)$. According to the hemodynamic parameters, MAP had 
statistically significant lower values from basal values in group $(\mathrm{B})$ and $(\mathrm{C})(\mathrm{P}<0.05)$. Also, group (C) showed a statistically significant decrease in MAP at 8, 9, 10, 12 and 14 minutes relative to both groups (A) and $(\mathrm{B})(\mathrm{P}<0.05)$ without significance between groups (B) \& (A) Figure (1).

However, HR had no statistically significant differences from basal values in or between the three groups Figure (2).

Regarding ephedrine requirements, there was a statistically significant difference between group (C) relative to groups (A) and (B) $(\mathrm{P}=0.01)$, As well there was a statistically significant difference in group (B) relative to group (A) (P> 0.05) Table (2).

On the other hand, there was no statistically significant difference between the three groups as regard atropine dose.

Regarding echocardiographic data of the left side of the heart, there was a significant decrease in LVEDV, LVESV, SV, CI and SVR after spinal anesthesia relative to before spinal anesthesia in all three groups $(\mathrm{P}<0.05)$ Table (3).

Furthermore, Group (C) showed a statistically significant decrease in LVEDV
( $\mathrm{P}=0.04)$, LVESV $(\mathrm{P}=0.03), \mathrm{SV}(\mathrm{P}=0.02)$, CI $(\mathrm{P}=0.02)$ and SVR $(\mathrm{P}=0.01)$ after spinal anesthesia relative to groups (A) \& (B), without significance between groups (B) \& (A) Table (3).

Regarding echocardiographic data of the right side of the heart, there was a significant decrease in RV diastolic volume, both the maximum and minimum diameters of IVC after spinal anesthesia relative to before spinal anesthesia in all three groups $(\mathrm{P}<0.05)$.

Also, group $\mathrm{C}$ showed a statistically significant decrease in RV diastolic volume $(\mathrm{P}=0.03)$, both the maximum $(\mathrm{P}=0.01)$ and minimum $(\mathrm{P}=0.02)$ diameters of IVC after spinal anesthesia, as compared to group (A) $\&$ (B), without significance between group (B) \& (A) Table (4).

Similarly, there were significant increase in PA diameter and decrease in PA systolic pressure, after spinal anesthesia relative to before spinal anesthesia in all the three groups $(\mathrm{P}<0.05)$. Moreover group $(\mathrm{C})$ showed a statistically significant difference regarding the increase in $\mathrm{PA}$ diameter $(\mathrm{P}=$ 0.04), after spinal anesthesia in comparison to group (A) \& (B) Table (4). 
Table (1): Demographic data

\begin{tabular}{lcccc}
\hline & Group A $(\mathbf{n}=\mathbf{2 9})$ & Group B $(\mathbf{n}=\mathbf{1 6})$ & Group C (n=5) & P value \\
\hline Age & $33.3 \pm 4.2$ & $32.9 \pm 5.1$ & $35.5 \pm 2.1$ & 0.25 \\
Sex (M/F) & $17 / 12$ & $9 / 7$ & $3 / 2$ & 0.41 \\
Weight (Kg) & $69.3 \pm 7.1$ & $73.1 \pm 6.3$ & $75.8 \pm 7.2$ & 0.39 \\
Height (cm) & $171.5 \pm 12.1$ & $169.1 \pm 10.2$ & $168.5 \pm 9.4$ & 0.18 \\
BSA & $1.73 \pm 0.09$ & $1.74 \pm 0.1$ & $1.72 \pm 0.7$ & 0.21 \\
BMI & $27.6 \pm 1.7$ & $28.3 \pm 1.2$ & $29.7 \pm 1.6$ & 0.17 \\
\hline
\end{tabular}

(Data are expressed as mean \pm standard deviation, or number)

$(\boldsymbol{A}: \mathrm{MAP}>80 \%, \boldsymbol{B}: \mathrm{MAP} \leq 80 \% \& \geq 70 \%, \boldsymbol{C}: \mathrm{MAP}<70 \%)$

( $\mathrm{P}$ value $\leq 0.05$ was considered statistically significant)

Table (2): Bromage score, Sensory level and Ephedrine dose

\begin{tabular}{lcccc}
\hline & Group A (n=29) & Group B (n=16) & Group C (n=5) & P value \\
\hline Highest sensory level & T6(T5-T8) & T6(T4-T8) & T5(T4-T6) * & 0.04 \\
Bromage score & $3(2-3)$ & $3(2-3)$ & $3(3)$ & 0.19 \\
Ephedrine dose (mg) & 0 & $11 \pm 5 \#$ & $18 \pm 4 *$ & 0.01 \\
\hline
\end{tabular}

(Data are expressed as median and range, or mean \pm standard deviation)

$(\boldsymbol{A}: \mathrm{MAP}>80 \%, \boldsymbol{B}: \mathrm{MAP} \leq 80 \% \& \geq 70 \%, \boldsymbol{C}: \mathrm{MAP}<70 \%)$

( $\mathrm{P}$ value $\leq 0.05$ was considered statistically significant)

*: Significance in group $\mathbf{C}$ relative to group A \& B

\#: Significance in group $\mathbf{B}$ relative to group A 
Table (3): Echocardiographic data of the left side of the heart

\begin{tabular}{|c|c|c|c|c|}
\hline & Group A $(n=29)$ & Group B $(n=16)$ & Group C $\quad(n=5)$ & $P$ value \\
\hline \multicolumn{5}{|c|}{ LA diameter $(\mathrm{cm})$} \\
\hline Pre & $2.73 \pm 0.02$ & $2.71 \pm 0.01$ & $2.76 \pm 0.03$ & 0.35 \\
\hline Post & $2.81 \pm 0.02$ & $2.81 \pm 0.04$ & $2.82 \pm 0.05$ & 0.21 \\
\hline \multicolumn{5}{|c|}{ LVEDD (cm) } \\
\hline Pre & $4.63 \pm 0.32$ & $4.59 \pm 0.41$ & $4.49 \pm 0.53$ & 0.41 \\
\hline Post & $4.44 \pm 0.59$ & $4.42 \pm 0.33$ & $4.42 \pm 0.41$ & 0.94 \\
\hline \multicolumn{5}{|c|}{ LVESD (cm) } \\
\hline Pre & $2.55 \pm 0.2$ & $2.64 \pm 0.33$ & $2.6 \pm 0.39$ & 0.76 \\
\hline Post & $2.88 \pm 0.22$ & $2.92 \pm 0.31$ & $3.12 \pm 0.13$ & 0.07 \\
\hline \multicolumn{5}{|c|}{ LVEDV (mL) } \\
\hline Pre & $94.3 \pm 12.3$ & $98.9 \pm 10.3$ & $92.13 \pm 9.22$ & 0.09 \\
\hline Post & $90.1 \pm 8.23 \dagger$ & $88.62 \pm 7.22 \dagger$ & $86.71 \pm 6.12 \dagger^{*}$ & 0.04 \\
\hline \multicolumn{5}{|c|}{ LVESV (mL) } \\
\hline Pre & $33.11 \pm 3.22$ & $34.33 \pm 2.98$ & $33.93 \pm 3.65$ & 0.21 \\
\hline Post & $29.71 \pm 2.11 \dagger$ & $27.11 \pm 4.43 \dagger$ & $26.33 \pm 3.98+*$ & 0.03 \\
\hline \multicolumn{5}{|c|}{ SV (mL) } \\
\hline Pre & $68.1 \pm 4.1$ & $70.3 \pm 5.1$ & $69.9 \pm 7.2$ & 0.61 \\
\hline Post & $65.2 \pm 6.8 \dagger$ & $62.7 \pm 3.8 \dagger$ & $60.9 \pm 7.1 \dagger^{*}$ & 0.02 \\
\hline \multicolumn{5}{|c|}{ CI $\left(\mathrm{L} / \mathrm{min} / \mathrm{m}^{2}\right)$} \\
\hline Pre & $3.08 \pm 0.2$ & $2.98 \pm 0.32$ & $2.99 \pm 0.43$ & 0.09 \\
\hline Post & $2.91 \pm 0.25 \dagger$ & $2.87 \pm 0.18 \dagger$ & $2.81 \pm 0.13 \dagger^{*}$ & 0.02 \\
\hline \multicolumn{5}{|c|}{ LVEF (mL) } \\
\hline Pre & $62.9 \pm 5.21$ & $61.65 \pm 6.33$ & $63.71 \pm 4.21$ & 0.24 \\
\hline Post & $64.16 \pm 4.66$ & $64.78 \pm 5.81$ & $65.33 \pm 6.89$ & 0.31 \\
\hline \multicolumn{5}{|c|}{ FS $(\%)$} \\
\hline Pre & $28.3 \pm 3.2$ & $28.9 \pm 2.8$ & $29.2 \pm 4.1$ & 0.12 \\
\hline Post & $27.1 \pm 4.2$ & $27.3 \pm 3.3$ & $27.9 \pm 3.8$ & 0.34 \\
\hline \multicolumn{5}{|c|}{ SVR (Woods) } \\
\hline Pre & $15.5 \pm 3.2$ & $15.8 \pm 2.2$ & $15.6 \pm 2.9$ & 0.41 \\
\hline Post & $14.4 \pm 2.1 \dagger$ & $13.9 \pm 2.5 \dagger$ & $13.1 \pm 1.5 \dagger^{*}$ & 0.01 \\
\hline
\end{tabular}

(Data are expressed as mean \pm standard deviation)

$(\boldsymbol{A}: \mathrm{MAP}>80 \%, \boldsymbol{B}: \mathrm{MAP} \leq 80 \% \& \geq 70 \%, \boldsymbol{C}: \mathrm{MAP}<70 \%)$

(P value $\leq 0.05$ was considered statistically significant)

*: Significance in group $\mathbf{C}$ relative to group A \& B

$\dagger$ : Significance relative to before spinal anaesthesia 
Table (4): Echocardiographic data of the right side of the heart

\begin{tabular}{|c|c|c|c|c|}
\hline & Group A $(n=29)$ & Group B $(n=16)$ & Group C $\quad(n=5)$ & P value \\
\hline \multicolumn{5}{|c|}{$\overline{\text { RA diameter }(\mathrm{cm})}$} \\
\hline Pre & $3.19 \pm 0.23$ & $3.17 \pm 0.17$ & $3.12 \pm 0.11$ & 0.34 \\
\hline Post & $3.07 \pm 0.15$ & $3.01 \pm 0.21$ & $2.99 \pm 0.13$ & 0.21 \\
\hline \multicolumn{5}{|c|}{ Basal RV diameter $(\mathrm{cm})$} \\
\hline Pre & $2.3 \pm 0.23$ & $2.35 \pm 0.31$ & $2.6 \pm 0.43$ & 0.25 \\
\hline Post & $2.7 \pm 0.39$ & $2.85 \pm 0.29$ & $2.91 \pm 0.26$ & 0.09 \\
\hline \multicolumn{5}{|c|}{ Mid RV diameter (cm) } \\
\hline Pre & $3.15 \pm 0.23$ & $3.18 \pm 0.22$ & $3.24 \pm 0.25$ & 0.07 \\
\hline Post & $3.29 \pm 0.31$ & $3.34 \pm 0.41$ & $3.43 \pm 0.36$ & 0.16 \\
\hline \multicolumn{5}{|c|}{ RV diastolic area $\left(\mathrm{cm}^{2}\right)$} \\
\hline Pre & $17 \pm 2.3$ & $18 \pm 3.3$ & $16.8 \pm 3.2$ & 0.17 \\
\hline Post & $21.5 \pm 2.8$ & $20.6 \pm 3.1$ & $19.8 \pm 2.9$ & 0.08 \\
\hline \multicolumn{5}{|c|}{ RV systolic area $\left(\mathrm{cm}^{2}\right)$} \\
\hline Pre & $8.6 \pm 0.9$ & $8.3 \pm 0.7$ & $7.9 \pm 1.1$ & 0.18 \\
\hline Post & $9.2 \pm 1.2$ & $9.7 \pm 1.4$ & $10.1 \pm 1.6$ & 0.07 \\
\hline \multicolumn{5}{|c|}{ RV volume (mL) } \\
\hline \multicolumn{5}{|c|}{ Diastole } \\
\hline Pre & $84.3 \pm 6.2$ & $83.5 \pm 7.2$ & $83.6 \pm 5.8$ & 0.54 \\
\hline Post & $79.4 \pm 8.25 \dagger$ & $76.15 \pm 7.4 \dagger$ & $73.5 \pm 7.2 \dagger *$ & 0.03 \\
\hline \multicolumn{5}{|c|}{ Systole } \\
\hline Pre & $24.03 \pm 5.3$ & $23.6 \pm 4.23$ & $26.8 \pm 6.4$ & 0.76 \\
\hline Post & $26.15 \pm 4.6$ & $28.2 \pm 6.4$ & $29.4 \pm 6.3$ & 0.08 \\
\hline \multicolumn{5}{|c|}{ PA diameter $(\mathrm{cm})$} \\
\hline Pre & $1.8 \pm 0.12$ & $1.77 \pm 0.21$ & $1.73 \pm 0.32$ & 0.32 \\
\hline Post & $2.1 \pm 0.2 \dagger$ & $2.2 \pm 0.15 \dagger$ & $2.3 \pm 0.12 \dagger *$ & 0.04 \\
\hline \multicolumn{5}{|c|}{ Systolic PA pressure (mmg) } \\
\hline Pre & $17.6 \pm 2.3$ & $17.2 \pm 1.9$ & $16.9 \pm 2.1$ & 0.12 \\
\hline Post & $16.3 \pm 1.8 \dagger$ & $15.9 \pm 1.7 \dagger$ & $15.8 \pm 1.3 \dagger$ & 0.08 \\
\hline \multicolumn{5}{|c|}{ IVC diameter (cm) } \\
\hline \multicolumn{5}{|l|}{ Max } \\
\hline Pre & $10.1 \pm 0.3$ & $9.8 \pm 0.5$ & $10.2 \pm 0.4$ & 0.26 \\
\hline Post & $8.6 \pm 0.6 \dagger$ & $9.1 \pm 0.8 \dagger$ & $9.4 \pm 0.7 \dagger^{*}$ & 0.01 \\
\hline \multicolumn{5}{|l|}{ Min } \\
\hline Pre & $6.4 \pm 0.8$ & $7.4 \pm 0.6$ & $7.1 \pm 0.9$ & 0.32 \\
\hline Post & $5.1 \pm 0.9 \dagger$ & $5.2 \pm 0.3 \dagger$ & $5.4 \pm 0.4 \dagger *$ & 0.02 \\
\hline
\end{tabular}

(Data are expressed as mean \pm standard deviation)

$(\boldsymbol{A}: \mathrm{MAP}>80 \%, \boldsymbol{B}: \mathrm{MAP} \leq 80 \% \& \geq 70 \%, \boldsymbol{C}: \mathrm{MAP}<70 \%)$

( $\mathrm{P}$ value $\leq 0.05$ was considered statistically significant)

*: Significance in group $\mathbf{C}$ relative to group A \& B

$\uparrow:$ Significance relative to before + spinal anaesthesia 


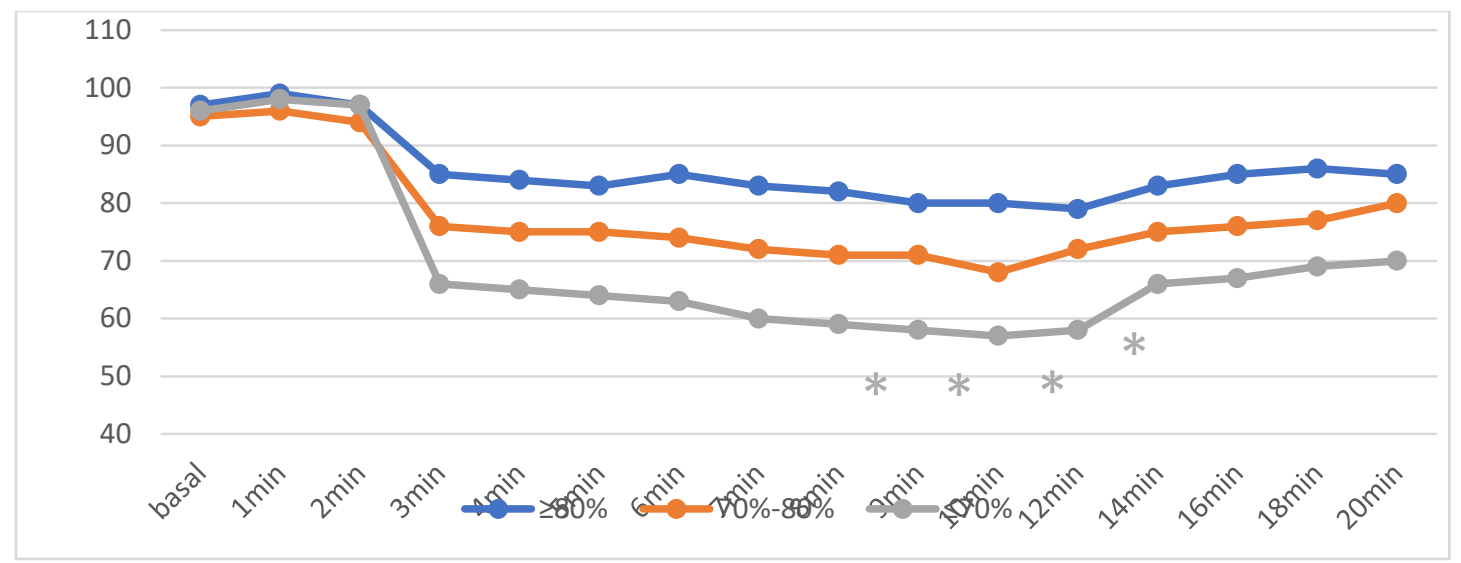

Figure (1): Mean values for peri-operative MAP (mmHg)

(Data are expressed as mean \pm standard deviation)

$(\boldsymbol{A}: \mathrm{MAP}>80 \%, \boldsymbol{B}: \mathrm{MAP} \leq 80 \% \& \geq 70 \%, \boldsymbol{C}: \mathrm{MAP}<70 \%)$

( $\mathrm{P}$ value $\leq 0.05$ was considered statistically significant)

*: Significance in group $\mathbf{C}$ relative to group A \& B

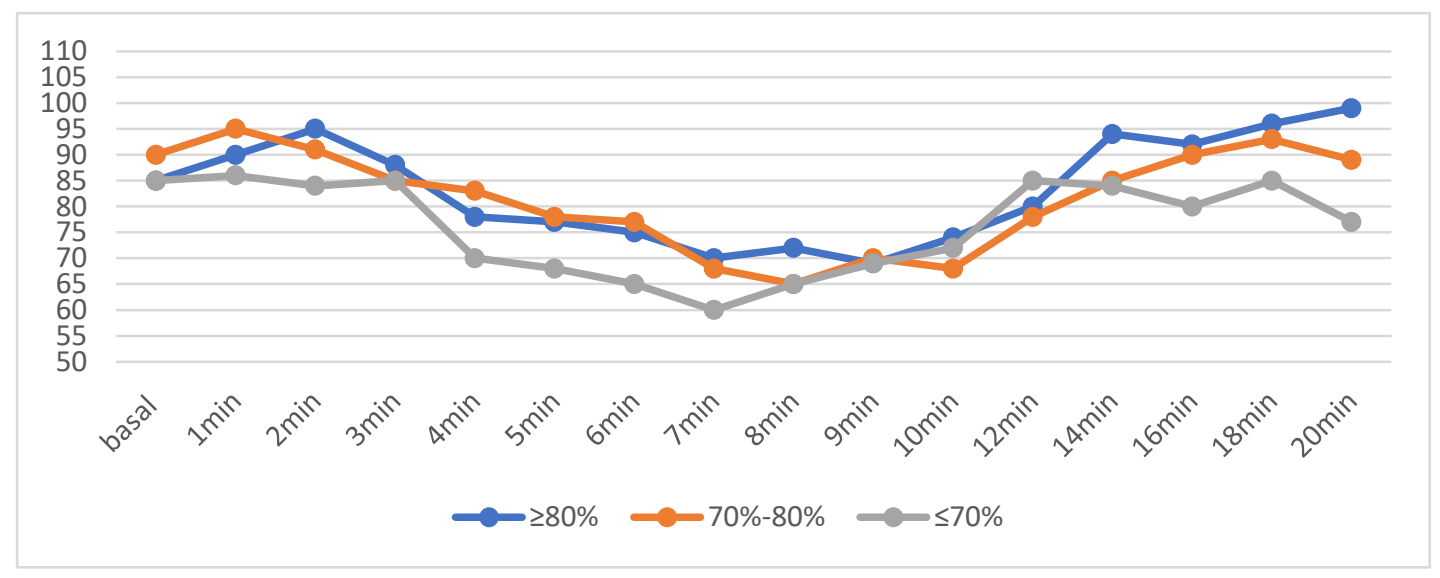

Figure (2): Mean values for peri-operative HR (beat/min)

(Data are expressed as mean \pm standard deviation)

$(\boldsymbol{A}: \mathrm{MAP}>80 \%, \boldsymbol{B}: \mathrm{MAP} \leq 80 \% \& \geq 70 \%, \boldsymbol{C}: \mathrm{MAP}<70 \%)$

( $\mathrm{P}$ value $\leq 0.05$ was considered statistically significant) 



\section{Discussion}

Spinal anesthesia is often associated with hemodynamic instability which can increase the risk of perioperative cardiac complications. Echocardiography has become the most informational point-of-care cardiac imaging modality for one's ability to analyze the structure and function of the heart, while providing medical and surgical interventions simultaneously helping to manage and improve patient's cardiac function (11).

In the current study, the hypotension associated with spinal anesthesia has been proportional to the sensory level. So, the highest sensory level has been notable when MAP $<70 \%$ of the basal value. However, HR records have not been related to these changes in MAP regardless of the sensory level. As well, ephedrine requirements have been remarkable when MAP was $<80 \%$ although the changes in echocardiographic data of the left and right sides of the heart have only been pronounced when MAP was $<70 \%$ of the basal value. Regarding echocardiographic monitoring the left sided heart variables have showed marked decrease in LVEDV, LVESV, SV, CI and SVR when MAP was $<70 \%$ of basal values. Similarly, the right sided heart variables have showed marked decrease in IVC diameters and RV diastolic volume, with increased PA diameter when MAP was < $70 \%$ of the basal values.

The present study has demonstrated that spinal anesthesia led to a decrease in MAP to a various degree according to the sensory level. This has been dominant in the correlation between the high sensory level (T5) and MAP $<70 \%$ of basal values. In accordance to this study, it is proved that profound sympathectomy when the sensory level was at T5 has caused a marked decrease in SVR and increase in PA diameter (3). This is compatible with several studies which stated that SVR is dramatically decreased when the sensory block is higher or equal to T6 (13).

Decrease in MAP passes in parallel to the changes in echocardiographic variables in the form of decreased SV, CI and SVR which may be attributed to reduced venous return as evidenced by decrease in IVC diameters and end diastolic ventricular volumes. These findings were in agreement with a study which also found similar results in the age group $<70$ years old. Otherwise, it was noted that the decrease in SVR was significantly higher in the age group $>70$ 
years old, which could be attributed to the age-related impairment of autonomic reflexes and blunted baroreflex sensitivity (1).

In contrast, another study has stated that there was no significant decrease in left ventricular volumes, this may be explained by the use of colloids as maintenance fluids intraoperatively and low dose of bupivacaine in spinal anesthesia (14).

The current study is consistent with several studies which reported that the systolic function has been preserved as evidenced by nonsignificant decrease in both EF and FS despite the high dose local anesthetics in the subarachnoid block, and this may be attributed to the young age of this study group (1) and (10). On the contrary, a study has stated that EF decreased after spinal anesthesia, this may be due to the old age study group of his study and not excluding ASA III patients from his study (15).

It is worth noting that the decrease in SV has not been compensated by an increase in $\mathrm{HR}$ and this may also explain the decrease in CO. This finding can be attributed to the sympathetic block induced by spinal anesthesia. However, there was no significant bradycardia requiring atropine administration in our study which may be due to the fact that the sensory level was less than T4, so not affecting the cardiac acceleratory fibers.

In the present study, the ephedrine requirements depending on MAP monitoring, have not always been reflected by significant changes in echocardiographic variables. So, when MAP was between $70 \%$ and $80 \%$ of basal values, there was no significant change in echocardiographic variables from those when MAP was $>80 \%$ of basal values. However, when MAP was $<70 \%$ of basal values, there was a remarkable change in echocardiographic variables from those of both when MAP was $>80 \%$ and between $70 \%-80 \%$ of basal values, which require the use of ephedrine. So, the administration of ephedrine depending only on MAP is erratic, and it is recommended to use it on an echocardiographic basis.

It is recommended to evaluate of the role of TTE as a portable accurate non-invasive monitoring device in emergency surgeries and to encourage its use in major operations with blood loss to assess its efficacy in guidance of hemodynamic management. Also, to applicate this study on an old age group of patients for early detection of age- 
related peri-operative cardiac complications with more frequent measurements to be recorded.

\section{Conclusion}

Transthoracic echocardiography has proved its efficacy as a monitoring tool in assessment and guiding the management of hemodynamic changes after spinal anesthesia. As well, management of this hemodynamic instability by vasopressors is better to be on an echocardiographic basis, not only on mere clinical non-invasive blood pressure monitoring.

\section{References}

1-Lairez O, Ferre F, Portet N, Marty P, Delmas C, Cognet $\mathrm{T}$, et al. Cardiovascular effects of low-dose spinal anesthesia as a function of age: An observational study using echocardiography. Anaesth Crit Care Pain Med 2015; 36: 112-119.

2-Rooke GA, Freund PR \& Jacobson AF. Hemodynamic response and change in organ blood volume during spinal anesthesia in elderly men with cardiac disease. Anesth Analg 1997; 85: 99-105.

3-Ferré V, Bradycardia, low blood pressure, and spinal anesthesia. Congrès national d'anesthésie et de réanimation 2011; 8: 121-126.

4-Kirov MY, Kuzkov VV \& Molnar Z. Perioperative hemodynamic monitoring Curr Opin Crit Care 2010; 16: 384-392.
5-Rhodes A, Cecconi M, Hamilton M, Poloniecki J, Woods J, Boyd O, et al. Goal-directed therapy in high risk surgical patients: a 15-year follow-up study. Intensive Care Med 2010; 36: 1327-1332.

6-Hamilton MA, Cecconi M \& Rhodes A. A systematic review and metaanalysis on the use of preemptive hemodynamic intervention to improve postoperative outcomes in moderate and high-risk surgical patients. Anesth Analg 2011; 112: 13921402.

7-Lang R M, Bierig M, Devereux R B, Flachskampf FA, Foster E, Pellikka PA, et al. Recommendations for chamber quantification: a report from the American Society of Echocardiography's Guidelines and Standards Committee and the Chamber Quantification Writing Group, developed in conjunction with the European Association of Echocardiography. J Am Soc Echocardiogr 2005; 18: 1440-1463.

8-Brederlau J, Kredel M, Wurmb T, Dirks J, Schwemmer U, Broscheit J, et al. Transesophageal echocardiography for non-cardiac surgery patients: superfluous luxury or essential diagnostic tool? Anaesthesist 2006; 55: 937-940.

9-Thys DM, Brooker RF, Cahalan MK, Connis RT, Duke PG , Nickinovich DG, et al. American Society of Anesthesiologists and Society of Cardiovascular Anesthesiologists Task Force on Transesophageal Echocardiography. An Updated Report on Transesophageal Echocardiography. Anesthiology 2010; 112: 1084-1096.

10-Dennis AT, Castro JM, Ong M, Carr C. Haemodynamics in obese pregnant women. Int $\mathrm{J}$ Obstet Anesth 2012; 21: 129-134. 
11-Cowie BS. Focused transthoracic 14-Cabrera Schulmeyer MC, Vargas J, la Maza De echocardiography in the perioperative period. J\& Labbe' M. Spinal anesthesia may diminish left Anaesth Intensive Care 2010; 38: 823-836. ventricular function: a study by means of intraoperative transthoracic echocardiography. Rev

12- Denault AY, Couture P, McKenty S. Boudreault D, Plante F, Perron R, et al. Perioperative use of transesophageal echocardiography by anesthesiologists: impact in noncardiac surgery. Can J Anaesth 2002; 49: 287-293.

13- Kamenik M. Spontaneous restoration of decreased systemic vascular resistance after spinal anaesthesia. Eur J Anaesthesiol. 2002; 19: 848-850.

Esp Anestesiol 2010; 57: 136-140.

15-Donati A, Mercuri G, Iuorio S. Sinkovetz L, Scarcella M, Trabucchi C, et al. Haemodynamic modifications after unilateral subarachnoid anaesthesia evaluated with transthoracic echocardiography. Minerva Anestesiol 2005; 71: 7581.

To cite this article: Sameh M Elsherbiny, Ahmed M Elaidy, Aboelnour M Badran, Ola T Abdeldayem. Transthoracic Echocardiographic Hemodynamic Assessment in Patients under Spinal Anesthesia in Lower Limb Surgery. BMFJ 2021;38 (1):41-54. DOI: 10.21608/bmfj.2020.34073.1282 